\title{
Fields of application for laser beam polishing of optical glasses
}

\author{
Anne-Marie Schwager ${ }^{*}$, Jens Bliedtner, Kerstin Götze, Michael Seiler, Tino Ritz, Christoph Letsch \\ Ernst-Abbe-University of Applied Sciences Jena, Carl-Zeiss-Promenade 2, 07745 Jena
}

Conventional manufacturing of freeform optics is expensive and elaborate. The laser beam as a polishing tool offers the possibility to produce optical surfaces fast and effective. [1] [2] The aim of new research on laser beam polishing of optical glasses is to achieve a polished surface finish irrespective of the surface geometrics. The carbon dioxide laser is applied to process premachined specimen with different roughness's. During the polishing process an infrared camera is necessary to monitor the temperature on the surface. An annealing process reduces the processrelated tensions. In addition, the cleaning process is investigated to minimize the surface damages. To characterize the surface topographic a white-light interferometer and a stylus instrument are applied.

Laser beam polishing of minerals glasses such as $\mathrm{N}-\mathrm{BK} 7^{\circledR}, \mathrm{BF} 33^{\circledR}$ and fused silica enables surface roughness of less than $\mathrm{Ra}<5 \mathrm{~nm}$ by form maintenance. By means of self-design setup, the adaption of laser beam polishing on glass cylinders, lenses or freeform is possible. As a result a parallel laser beam with a diameter of $12.65 \mathrm{~mm}$ is applied to process tilted surfaces up to $45^{\circ}$. With a laser parameter modulation, the angle-dependent absorption depending on the intensity of the laser radiation is considered.

The picture shows a laser beam polished lens surface made of optical glass $\mathrm{N}-\mathrm{BK} 7^{\circledR}$.

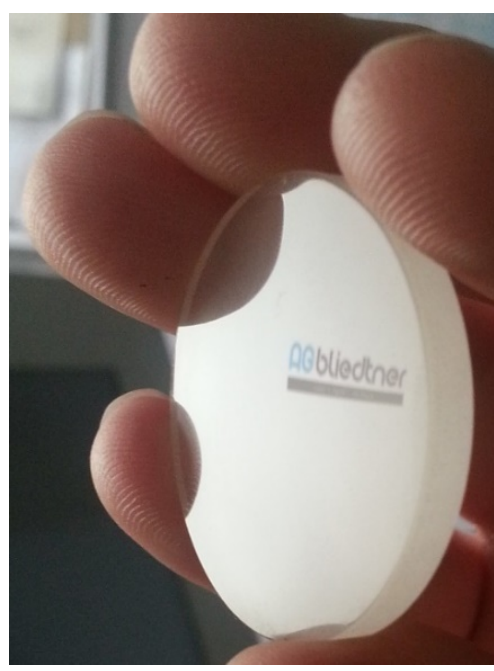

1. Bliedtner, J., Müller H. and Barz A.: "Lasermaterialbearbeitung, Grundlagen- Verfahren- Anwendungen- Beispiele “ Carl Hanser Verlag , 2013. - ISBN 978-3-446-42168-4.

2. Hecht, K.: “Entwicklung eines Laserstrahlpolierverfahrens für Quarzglasoberflächen“, Dissertation, Ilmenau, Universitätsverlag Ilmenau

This work has been partially funded by the German Federal Ministry of Education and Research as part of the funding program Forschung an Fachhochschulen. Funding reference: 13FH003IA6 "OpTec4.0". The authors wish to thank the project partners for supporting the investigations.

\footnotetext{
* Corresponding author: anne-marie.schwager@eah-jena.de
} 